This is a postprint version of the following published document:

J. Gonzalez-Benito, J. C. Cabanelas, J, A. J. Aznar, M. R. Vigil, J. Bravo y J. Baselga (1996). Surface Characterization of Silanized Glass Fibers by Labeling with Environmental Sensitive Fluorophores. Journal of Applied Polymer Science, 62 (2), pp. 375-384.

DOI: $10.1002 /$

(SICI)1097-4628(19961010)62:2<375::AIDAPP12>3.0.CO;2-0

(C) Wiley, 1996 


\title{
Surface Characterization of Silanized Glass Fibers by Labeling with Environmental Sensitive Fluorophores
}

\author{
J. GONZALEZ-Benito, J. C. CABAnelas, A. J. AZNAR, M. R. VIGIL, J. BRAVO, and J. BASELGA* \\ *Dpto. Ingenieria, Universidad Carlos III de Madrid, C/Butarque 15, 28911 Leganes, Spain
}

\begin{abstract}
Glass fibers have been treated with -y-aminopropyl-triethoxysilane (APES) through different silanizating procedures, which include APES aqueous solutions and APES vapor adsorption. Transmission Fourier transform IR (FTIR) measurements have been performed on the silanized samples to characterize the silanization reaction. Dansyl-sulfonamide conjugates have then been formed by reaction of dansyl chloride in dimethylformamide solution with the amine functionality's immobilized on the glass fiber surface. Steady-state and time- resolved fluorescence measurements have been performed on dansylated samples. A de-pendence of the fluorescence intensity and the wavelength of the maximum emission on the silanization procedure has been observed. Good fits of the fluorescence decays of dansyl labels are found when biexponential functions are used for deconvolution, whereas the decay of dansylamides in fluid solution is single exponential. A two-state model for the solid solvent relaxation seems to apply for this samples. Several surface structural changes produced by the different silanization methods have been proposed. FTIR results support the
\end{abstract} conclusions drawn from fluorescence measurements.

\section{INTRODUCTION}

Glass fibers are probably the most widely used reinforcing fillers in polymer composites. On an industrial scale, they are usually obtained by melt spinning. Because of their high abrasiveness, they are surface treated with complex chemical formulations that include lubricants, film formers, and adhesion promoters as main components. A general handling improvement is attained when glass fibers are coated in this way, and the presence of coupling agents enhances also the adhesion and durability of the fiber/ polymer matrix interface. ${ }^{1} \underline{3}$

Among the great variety of coupling agents, organotriethoxysilanes are of prime importance. In acidic or, more commonly, basic conditions, ethoxysilanes hydrolyze and condense with surface silanol groups. Initially, it was assumed that this equilibrium chemical reaction contributes to form chemical links between the glass substrate and the organic functionality of the silane residues; successive con- densation steps would form a polyorganosiloxane layer all around the fibers. Unfortunately, it has been proved that triethoxysilanes condense over glass fibers, but instead of uniform layers they form islands of irregular and heterogeneous structure and, probably, composition; at least such is the case for $-y$ aminopropy 1 -triethoxysilane (APES ).$^{4} 7$

The accessibility of the organic functionality once the silane is condensed on the glass fiber surface, the diffusion of matrix polymeric chains into the polyorganosiloxane layer, and the structure of the silanized surface at a molecular and supramolecular level are topics of current interest, both in applied and basic research, s- ${ }^{11}$ because of their important role in determining the mechanical and durability properties of composites. Techniques as quantitative Fourier transform IR ( FTIR ), X-ray photoelectron spectroscopy, inelastic electron tunneling spectroscopy, secondary ion mass spectroscopy, X-ray photoelectron spectroscopy, and positron annihilation spectroscopy were usually used in this type of studies. On the other hand, fluorescence techniques are becoming powerful tools in studying polymer systems as the polyorganosiloxane fiber coatings here considered. 
The aim of this work is to analyze the surface structure of silanized glass fibers using molecular fluorescence techniques and correlating them with FTIR measurements. APES is used as the silanizating agent; and several silanization methods are used to develop different coating structures on commercial glass fibers. The fluorescent probe selected for this work has been dansyl chloride because its ability to form stable fluorescent adducts with the amine functionality's of APES, which are sensitive to the polarity of the fluorophore environment.

\section{EXPER IMENT Al}

\section{Materials}

E-type commercial glass fibers from Vetrotex were used. APES and 5-dimethylamino-1-naphtalenesulfonyl chloride (DNS) were purchased from Dynamic Nobel and ICN, respectively, and used without further purification. Toluene was distilled over sodium just before use. The other solvents were high quality products of fluorimetric grade.

\section{Sample Pretreatments}

Before silanization, glass fibers were calcinated at $450^{\circ} \mathrm{C}$ for $1 \mathrm{~h}$ to remove organic matter from the surface. Regeneration of surface silanol groups was performed by treating the fibers with a boiling $10 \%$ $\mathrm{HCl}$ aqueous solution for $3 \mathrm{~h}$. After activation, samples were washed with distilled water for complete removal of $\mathrm{Cl}$ - and then dried at $120^{\circ} \mathrm{C}$ for $1 \mathrm{~h}$.

\section{Silanization}

Table I summarizes the different silanization procedures used to develop different layer structures: APES vapor adsorption, which was performed by treating the fibers with an APES saturated airstream at $150^{\circ} \mathrm{C}(60 \% \mathrm{RH})$; reflux in APES toluene solutions; and room temperature treatment of fibers with a 2\% APES aqueous solution.

In the first method, silanization time was varied in the range 10 to $60 \mathrm{~min}$. In the toluene reflux method, silanization time was kept constant and high ( $16 \mathrm{~h}$ ); assuming that glass fibers contain 6 silanol groups $/ \mathrm{nm}^{2}$ and that their BET specific surface is $100 \mathrm{~m}^{2} / \mathrm{g}$ (after acidic activation ), the number of silanol groups/g of fiber is estimated as 1 $\mathrm{mmol} / \mathrm{g}$. The concentration of APES in the silanizating toluene solution was set so as to be approx- imately stoichiometric with respect to the fiber silanol content.

The whole silanization process consisted of the following steps: silanization reaction through the different methods mentioned above; heating at $120^{\circ} \mathrm{C}$ for $1 \mathrm{~h}$, for polycondensation of ethoxy residues and drying; extraction of unreacted silane with dried toluene for $3 \mathrm{~h}$; and vacuum drying at room temperature for $14 \mathrm{~h}$.

\section{Dansylation}

Well-dried silanized glass fibers were put in contact for $1 \mathrm{~h}$, at room temperature, with DNS solutions $\left(10-^{2} M\right)$ in dimethylformamide (DMF). Then, the fibers were exhaustively washed with solvent and vacuum dried for at least $14 \mathrm{~h}$.

\section{FTIR Measurements}

Transmission FTIR measurements were performed on a Mattson Galaxy 3000; samples were grinded, diluted with $\mathrm{KBr}$, and press molded in an evacuated press at $20 \mathrm{~atm}$ to form disks of $18 \mathrm{~mm}$ diameter. The spectral conditions were 100 scans, ranging from 400 to $4000 \mathrm{~cm}^{-1}$, and $2 \mathrm{~cm}^{-1}$ resolution.

\section{Fluorescence Measurements}

Steady-state fluorescence measurements were performed on a Perkin-Elmer LS-3 fluorimeter. An optical fiber device, designed in our laboratory, was used to either excite or collect fluorescence. Spectral conditions were $10 \mathrm{~nm}$ excitation and emission bandpass, and , IExe $=354 \mathrm{~nm}$; uncorrected spectra were recorded from 360 to $600 \mathrm{~nm}$.

Fluorescence decays of dansyl adducts were obtained by time-resolved fluorimetry using the singlephoton counting technique on a modified PRA fluorimeter. An Edinburgh nF900 flashlamp was used with $\mathrm{N}_{2}$ as filling gas. The optimum lamp conditions were $1.5 \mathrm{~atm}, 30 \mathrm{kHz}, 6 \mathrm{kV}$; the typical fwhm of the lamp pulse was $1.8 \mathrm{~ns}$. Front face excitation was used for solid samples; the excitation wavelength was set at $354 \mathrm{~nm}$ and the emission wavelength at the maximum obtained in the steady-state spectra. In some experiments, other wavelengths were used as stated in the text. Counts of $10^{4}$ were collected, at least, in the maximum. 


\section{RESU LTS AND DISCUSSION}

\section{FTIR Spectra}

The effect of the calcination and activation treatments is shown in Figure 1(a), where the high frequency region of the spectra for the received commercial samples, calcinated samples, and activated samples are compared. Calcination substantially reduces the water content of the fibers as reflected by the reduction of the water band (3400-3500 $\mathrm{cm}_{-1}^{-1}$ ). The water content is recuperated in the activation step. The small shoulder at 3620-3630 $\mathrm{cm}^{-1}$, which is assigned to stretching of globular silanols, ij reveals that fiber activation increases the $\mathrm{Si-OH}$ surface content. Calcination and activation also induce some changes in the low frequency region of the FTIR spectra, as shown in Fig. 1(b). The band centered at $1050 \mathrm{~cm}^{-1}$,which is assigned to stretching of $\mathrm{Si}-\mathrm{O}-\mathrm{Si}$ bonds, broadens and shifts about $20 \mathrm{~cm}^{-1}$ to low frequencies with calcination. After acid activation, this band sharpens, recovering its initial shape. This broadening effect may be due to formation of strained siloxane cyclics, associated to the high temperature dehydrating treatment. ${ }^{14}$ The spectra of the activated samples shows a band at $520 \mathrm{~cm}^{-1}$, which is present as a shoulder of the 470 $\mathrm{cm}-{ }^{1}$ band in the commercial samples but is absent in the calcinated ones. As will be seen later, the band at $520 \mathrm{~cm}-$ disappears also when the activated samples are silanized no matter what silanization time or procedure are used. This result suggests that this band may be associated with the presence of silanol groups.

In Figure 2, the FTIR spectra of samples silanized by vapor adsorption of APES, at different reaction times, are presented. For the purpose of comparison,

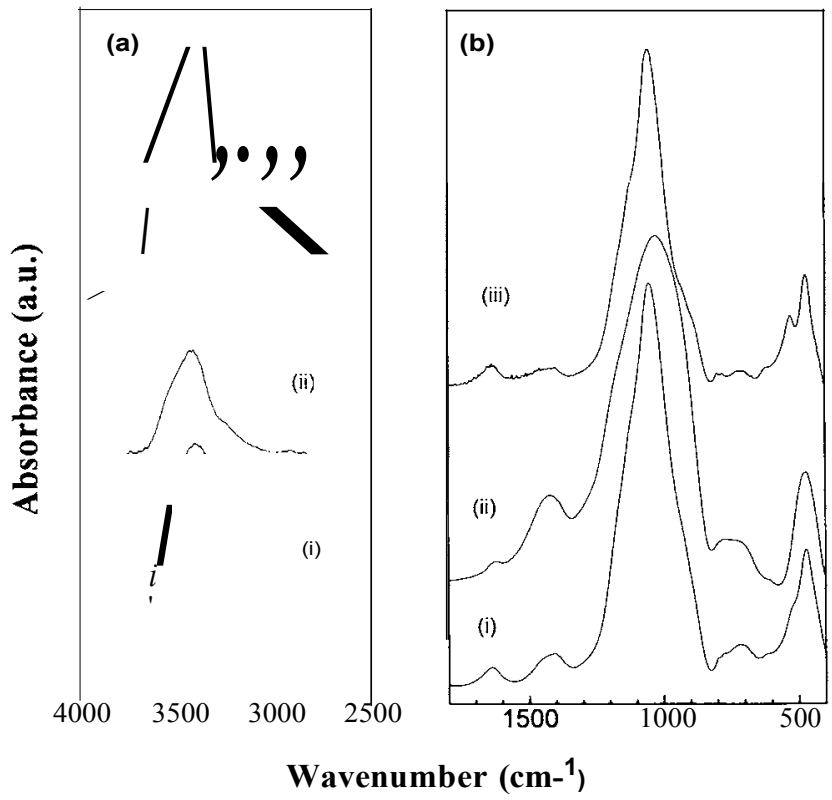

Figure 1 High (a) and low (b) energy FTIR spectra of glass fibers: (i) as received samples, (ii) calcinated at $450^{\circ} \mathrm{C}$ for 1 hour, (iii) activated fibers with boiling $10 \% \mathrm{HCI}$ for $3 \mathrm{~h}$.

the spectrum of activated fibers is presented also. All spectra are normalized, taking as a reference ${ }^{15}$ the $\mathrm{Si}-\mathrm{O}$ deformation band at $470 \mathrm{~cm}^{-1}$. As it can be seen, in the first step of the process, the water that is contained in the vapor stream is preferen tially adsorbed over the fiber surface, as reflected by the enhancement of the water deformation band at $3400 \mathrm{~cm}-ı$. The disappearance of the shoulder at $3630 \mathrm{~cm}_{-1}$ ( silanol signal) and the broadening of the $\mathrm{Si}-\mathrm{O}-\mathrm{Si}$ stretching band show that some silane becomes grafted to the surface. At longer silanization

Table I Silanization Procedures and Experimental Conditions

\begin{tabular}{|c|c|c|c|}
\hline Silanization Method & $\begin{array}{c}\text { Silanization } \\
\text { Time } \\
(\min )\end{array}$ & $\begin{array}{c}\text { Polymerization } \\
\text { Temperature } \\
\text { (oC) }\end{array}$ & $\begin{array}{c}\text { Sample } \\
\text { Code }\end{array}$ \\
\hline \multirow[t]{3}{*}{ APES vapor adsorption $\left(150^{\circ} \mathrm{C}\right)$} & 10 & 120 & VAP1O \\
\hline & 30 & 120 & VAP30 \\
\hline & 60 & 120 & VAP60 \\
\hline \multirow[t]{2}{*}{ Reflux of APES toluene solution } & 800 & 120 & TOL120 \\
\hline & & 60 & TOL60 \\
\hline \multirow[t]{6}{*}{ APES aqueous solution ( $2 \%)$} & 5 & 120 & AQ5-120 \\
\hline & 15 & 120 & AQ15-12C \\
\hline & 30 & 120 & AQ30-12C \\
\hline & 5 & 60 & AQ5-60 \\
\hline & 15 & 60 & AQ15-60 \\
\hline & 30 & 60 & AQ30-60 \\
\hline
\end{tabular}


(a)

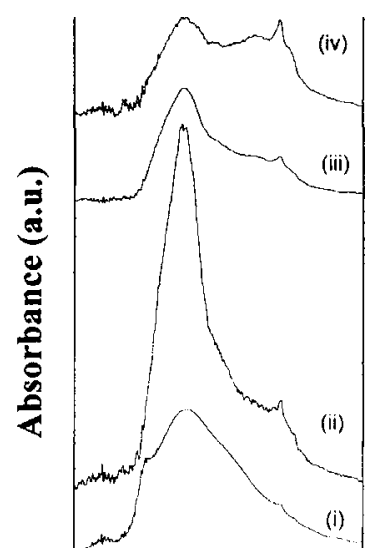

4000 (b)

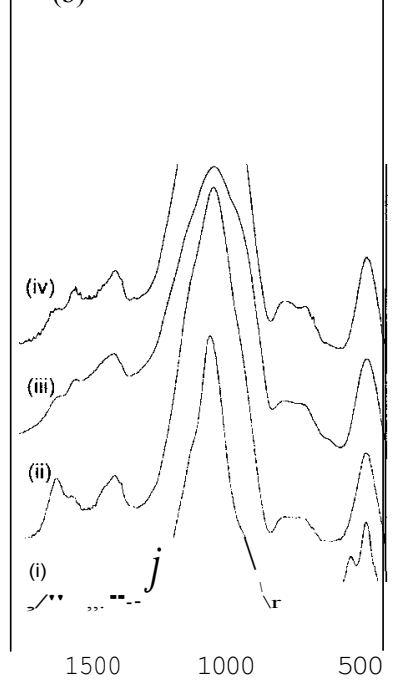

Waven umber $\left(\mathrm{cm}^{1}{ }^{1}\right)$
Figure 2 High (a) and low (b) energy FTIR spectra of glass fibers silanized by APES vapor adsorption, at different reaction times: (i) activated samples, (ii) $10 \mathrm{~min}$, (iii) $30 \mathrm{~min}$, (iv) $60 \mathrm{~min}$.

times, the adsorbed water becomes displaced by APES and more intense bands due to organic groups are found. For example, in the high frequency region of the spectra and overlapped with the water band, it can be observed as a broad band (3000-3500 cm-i) that is assigned to asymmetric and symmetric aliphatic N-H stretching vibration; at $2935 \mathrm{~cm}^{-1}$, the typical asymmetric vibrations of $\mathrm{CH}_{2}$ groups are observed also. In the low frequency region of the spectra, it can be observed that the $\mathrm{Si}-\mathrm{O}-\mathrm{Si}$ stretching band becomes greatly deformed due to the contribution of the $\mathrm{Si}-\mathrm{O}-\mathrm{C}$ stretching of uncondensed ethoxy groups (very strong), $\mathrm{Si}-\mathbf{C}$ deformation of propylamine groups, and C-N stretching of primary aliphatic amine functionality's

$\mathrm{Si}-\mathrm{O}-\mathrm{Si}$ band for the three reaction times shows that at 10 and $30 \mathrm{~min}$, a great number of uncondensed ethoxy residues are grafted onto the fiber surface. At $60 \mathrm{~min}$, this band becomes less deformed, indicating that the contribution of the more intense $\mathrm{Si}-\mathrm{O}-\mathrm{C}_{2} \mathrm{H}_{5}$ stretching band decreases. This fact suggests that during the adsorption step, either grafting or polymerization of APES simultaneously occur.

Silanization by a $2 \%$ APES aqueous solution at room temperature does not give rise to any new signal in the FTIR spectra [Fig. 3 (a) and (b)], but significative changes are observed in the shape and relative intensity of the bands mentioned above. The enhancement of the methylenic signals at $2850 \mathrm{~cm}^{-1}$ and $2935 \mathrm{~cm}^{-1}$ [Fig. 3( a )] reveals a great amount of grafted organic matter. In this region of the spectra, there are also present the stretching bands of the protonated and unprotonated amine groups that overlap with the water bands and do not allow its study. For this reason, it is more convenient to study the deformation region around 1600-1500 $\mathrm{cm}^{-1}$. In Fig. 3 (b), a small band can be observed at 1640 $\mathrm{cm}^{-1}$ for the spectrum of the activated sample, which is assigned to water deformation. This band is also present as a small shoulder for the samples treated 5 and $15 \mathrm{~min}$, but for this sample a stronger band at $1500 \mathrm{~cm}{ }^{1}$ is observed. This band is assigned to

of $\mathrm{NH}$ ! groups. It is interesting to note that for the samples silanized by vapor adsorption [Fig. 2 (b) ], there is no absorption band at $1500 \mathrm{~cm}^{-1}$, although a small band at $1570 \mathrm{~cm}-{ }^{1}$ can be detected. This last band is assigned to unprotonated amine deformation vibrations.

The distortion of the $\mathrm{Si}-\mathbf{O}-\mathbf{S i}$ stretching band allows a discussion of the grafting of APES onto the fiber surface, as in the case of samples silanized by vapor adsorption. InFigure 3 ( b ), it can be observed that the fraction of uncondensed residues grows with the reaction time; the greatest amount is found for the greatest silanization time $(30 \mathrm{~min})$, revealing

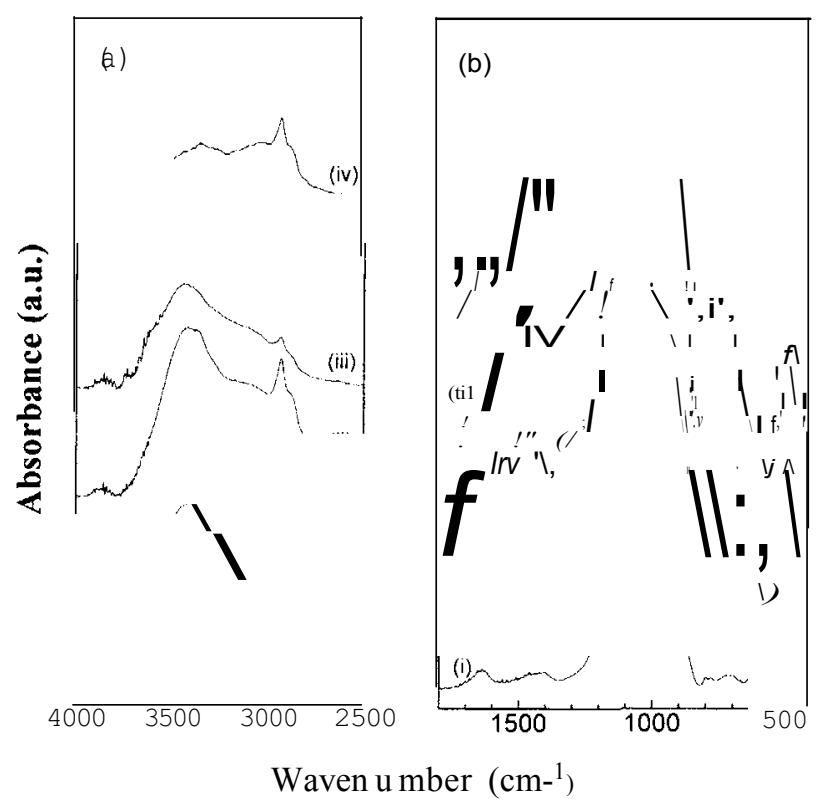

Figure 3 High (a) and low (b) energy FTIR spectra of glass fibers silanized by a $2 \%$ APES aqueous solution, at different reaction times: (i) activated samples, (ii) $5 \mathrm{~min}$, (iii) $15 \mathrm{~min}$, (iv) $30 \mathrm{~min}$. Polymerization at $120^{\circ} \mathrm{C}$. 
that, as expected because of the low temperature used, there is no appreciable polymerization during the silanization process.

For a group of samples silanized by aqueous solution of APES, a low polymerization temperature $\left(60^{\circ} \mathrm{C}, 1 \mathrm{~h}\right)$ was used also to check if a polymerization temperature below the boiling temperature of water was a critical parameter. The FTIR spectra of this samples (not shown) are almost identical to the samples polymerized at high temperature, but differ in the higher fraction of uncondensed ethoxy groups.

In Figure 4, the FTIR spectra of samples silanized by the different methods discussed above are presented for the purpose of comparison. With respect to the spectrum of the sample silanized by reflux of a dry toluene APES solution, which is presented also, no appreciable signal of protonated or unprotonated amine deformation vibrations ( 1500 and $1570 \mathrm{~cm}^{-1}$, respectively ) are observed. On the contrary, the absence of the characteristic silanol signals at $3620 \mathrm{~cm}^{-1}$ and at $520 \mathrm{~cm}^{-1}$, and the characteristic distortion of the $\mathrm{Si}-\mathrm{O}-\mathrm{Si}$ stretching band, which resembles the one of samples silanized $30 \mathrm{~min}$ by vapor adsorption, indicate that some APES condensation has taken place, although the coating content may be very small.

The comparison of the three methods presented in Figure 4 allows the next main conclusions. First, in all the three methods, APES chemically grafts onto the fiber surface via surface silanol condensation. Second, the maximum polyorganosiloxane content is obtained by reaction with APES aqueous solutions, although this method leads to a slightly crosslinked coating with a great fraction of uncondensed ethoxy residues ( under our experimental conditions ). Third, the maximum crosslinking degree of the polyorganosiloxane layer is obtained by the vapor adsorption method. Finally, only in the APES aqueous solution method is observed protonated amine.

\section{Steady-State Fluorescence}

Dansyl chloride is a well-known polarity-sensitive fluorophore. ${ }^{16}$ It has been widely used in polymer studies ${ }^{11}{ }_{-}{ }^{19}$ as well as in polar site determinations and energy transfer studies in well-characterized silica supports. ${ }^{20}{ }^{22}$ It is not fluorescent unless it reacts with nonprotonated amines. The resulting amide conjugates are strongly fluorescent, having large Stokes shifts along with environmental sensitive quantum yields and emission maxima. In certain solvents such as the one used in this work

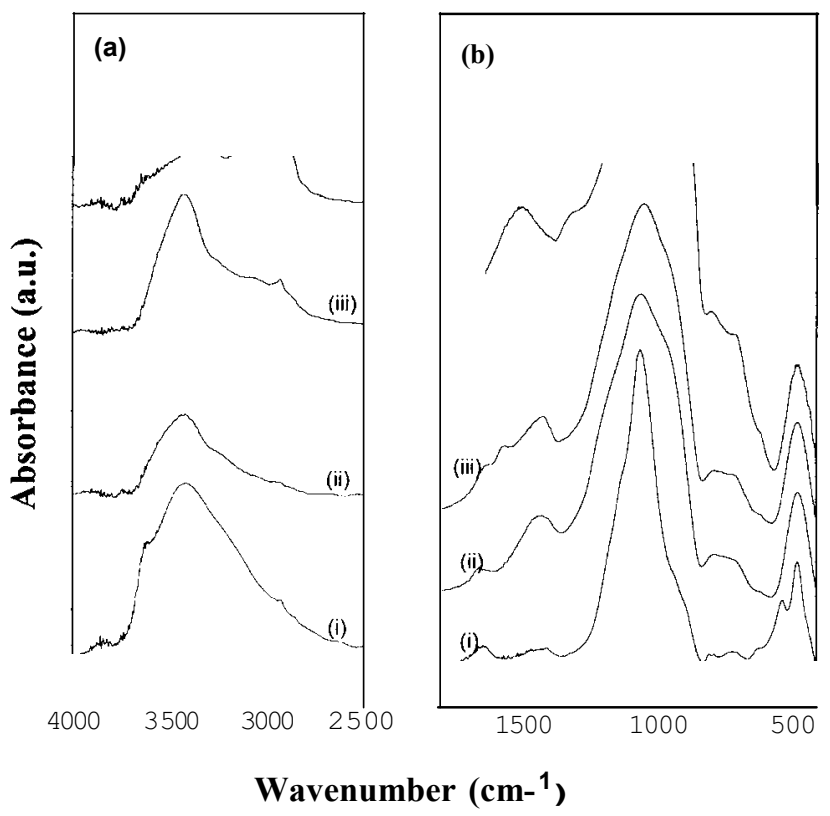

Figure 4 High (a) and low (b) energy FTIR spectra of glass fibers silanized by different methods: (i) activated samples, (ii) silanization by reflux of dry toluene APES solution, (iii) silanization by APES vapor adsorption (30 min), (iv) silanization by a $2 \%$ APES aqueous solution (30 $\mathrm{min})$.

(DMF), strong fluorescence of dansyl chloride solutions is observed, probably due to exciplex emission; some care must therefore be taken to completely remove the solvent before analysis of the amine conjugate.

Amine functionality's are expected to be randomly distributed through the fixed polyorganosiloxane layer, so that dansyl emission should reflect the average properties of the layer. Since the latter is a consequence of the silanization procedure, different fluorescence responses should be expected for the different silanization treatments used.

Figure 5 depicts the fluorescence spectra of dansylated glass fibers silanized by vapor adsorption at different reaction times. In Figure 6, fluorescence spectra of dansylated fibers silanized by aqueous APES solutions are presented. Samples silanized by reflux of a toluene solution (second method of the experimental part ) did not give any emission at all, meaning that silanization was so inefficient that no dansylamide could be formed and therefore any fluorescence spectra could be measured. The fact that no measurable signal of amine was found by FTIR may explain the nonfluorescent behavior of this sample.

In the two figures mentioned, which correspond to fluorescent samples, a unique broad band peaking 


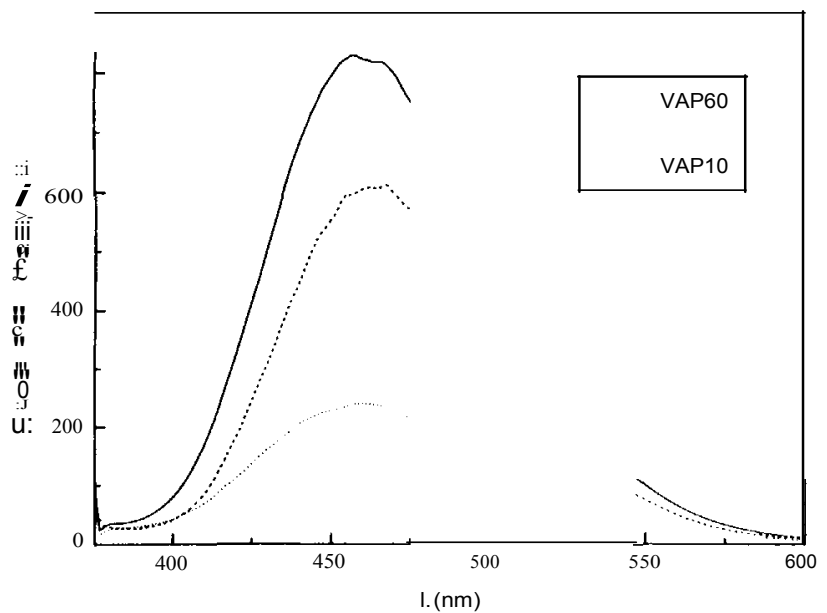

Figure 5 Steady-state fluorescence spectra for dansylated fibers silanized by adsorption of APES vapor at different reaction times.

in the range $440-460 \mathrm{~nm}$, and with a bandwidth of $3700 \pm 150 \mathrm{~cm}^{-1}$, is observed. This band is assigned to the fluorescence emission of the sulfonamide formed by reaction of the propylamine residue of the coupling agent and the dansyl chloride group.

In Table II, the wavelength at the maximum ( AMAX) and the maximum intensity (IMAX) for all the samples studied in this work are presented. The main results that can be considered from inspection of Figures 5 and 6 and Table II can be summarized as follows. Samples silanized by vapor adsorption give the maximum fluorescence intensity when compared with other treatments; a slight red shift is observed when increasing silanization time from 10 to $30 \mathrm{~min}$, remaining practically constant at 60 min. Samples silanized by treatment with APES aqueous solution show a more pronounced red shift, independently of the polymerization temperature. The fluorescence intensity of samples polymerized at $120^{\circ} \mathrm{C}$ is about $25 \%$ higher than samples polymerized at $60^{\circ} \mathrm{C}$. The wavelength at the maximum for samples silanized by APES aqueous solutions is lower than the corresponding to vapor adsorption treatment, independently of the reaction time.

The increasing trend of the fluorescence intensity with reaction time for all the sample sets may be due simply to an increase in the grafted APES content and, therefore, in the number of amine groups susceptible to form the dansylamide adduct. Nevertheless, as mentioned in the above discussion of FTIR results, it would be expected to find the maximum fluorescence intensities in the samples with the maximum polyorganosiloxane content, that is to say, in the samples silanized by APES aqueous

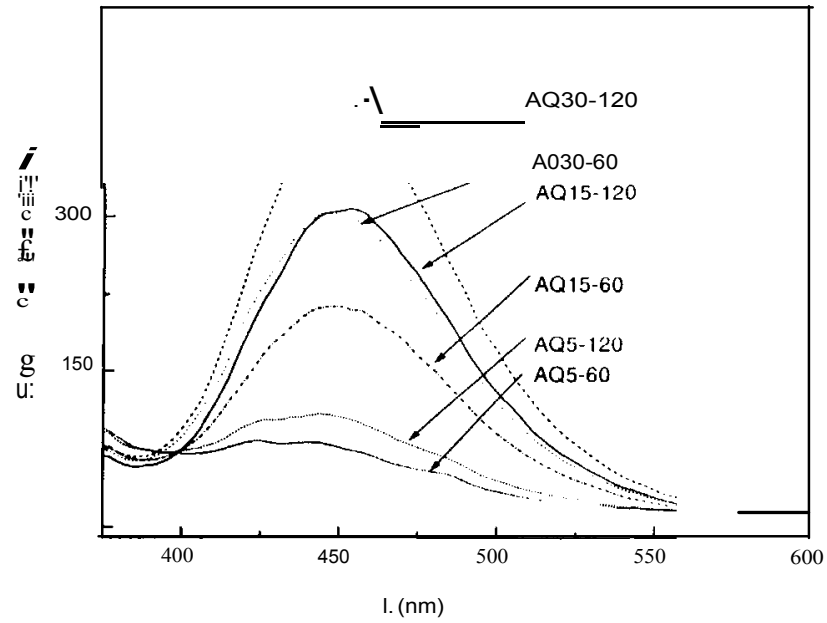

Figure 6 Steady-state fluorescence spectra for dansylated fibers silanized by a $\%$ APES aqueous solution and polymerized at $60^{\circ} \mathrm{C}$ (AQ5-60, AQ15-60, and AQ30-60) or $120^{\circ} \mathrm{C}$ (AQ5-120, AQ15-120, and AQ30-120).

solutions, and that is not the case. The reason of this discrepancy may be due to the great amount of protonated amine groups that are present in the samples silanized by aqueous solutions; as stated above, dansyl chloride may form stable adducts with free aliphatic amines at basic $\mathrm{pH} .{ }^{16}$ The conditions used in this work for making the adducts were selected to prevent hydrolysis of the siloxane grafted onto the fibers and may be not so basic so as to neutralize the protonated amine groups. As a result, only a small fraction of the amine groups may be forming stable conjugates and therefore only the general trends in the fluorescence intensity variations may be compared between the two methods and not the absolute values.

With respect to the differences found in AMAX, let us fix our attention to the samples silanized by

Table II Wavelength at the Emission Maximum and Maximum Intensity for Dansylated Samples

\begin{tabular}{lcr}
\hline Sample & $\begin{array}{c}\text { IMAX } \\
(\mathrm{nm})\end{array}$ & $\begin{array}{r}\text { /MAX } \\
\text { (a.u. })\end{array}$ \\
\hline VAP1O & $458 \pm 2$ & 239 \\
VAP30 & $462 \pm 2$ & 607 \\
VAP60 & $461 \pm 2$ & 820 \\
AQ30-120 & $450 \pm 2$ & 408 \\
AQ1fi-120 & $445 \pm 2$ & 303 \\
AQfi-120 & $441 \pm 2$ & 107 \\
AQ30-60 & $452 \pm 2$ & 306 \\
AQ15-60 & $447 \pm 2$ & 213 \\
AQfi-60 & $438 \pm 2$ & 80 \\
\hline
\end{tabular}


aqueous solutions of APES. The wavelength at the maximum for the dansyl group in pure APES, at room temperature, has been measured and resulted to be $461 \pm 2 \mathrm{~nm}$. The same value is obtained for cyclohexane, which has approximately the same solubility parameter ${ }^{23} \mathrm{bcH}=16.8 \mathrm{MPa}^{112}$, bAPES $=17.1 \mathrm{MPa}^{112}$ ). In this low viscosity solvent, the emission of the dansyl moiety corresponds to a relaxed state, in which solvent molecules surrounding the excited fluorophore orient its dipoles in a time scale lower than the dansyl lifetime. The emission of dansyl attached to fibers is blue shifted with respect to the emission from solutions of pure APES. The fact that the environment surrounding the fluorophore in the fibers is really rigid and considering that the polarity, in terms of the solubility parameter, is scarcely changed by the polycondensation reaction, allows the assumption that the observed blue shift effect reflects that the dansyl group attached to the fibers emits from a high energy unrelaxed state $^{24}$; that is to say, the surrounding dipoles of the solid solvent relax in a time scale comparable or larger than the lifetime of the fluorophore.

To check if this model explains our experimental results, some time resolved fluorimetric measurements, which are discussed below, have been performed.

\section{Time Resolved Fluorimetry}

The initial attempt of fitting the decays gave the optimum fit for triexponential functions of the form

$A+J_{1} B ; \exp \{-;\}$ with a very high short time

component $(<0.3 \mathrm{~ns})$; this component was assigned to reflection due to the glass nature of the substrate. After mathematical treatment of the data for eliminating the reflection component, good fits were found for biexponential functions, with residuals without trend ( Fig. 7 ) . Table III summarizes the lifetimes $T$; and integrated amplitudes $w$; (defined as $T ; B ; / L T ; B$; and expressed as percentage $)$; in the last two columns of Table III, average fluorescence lifetimes, ( $\mathrm{T}$; ) (defined as $L T B$;/ $L T ; B$; ) and relaxation times, $T R$, which will be discussed below, have also been presented.

The reported lifetime for dansyl sufonamides ${ }^{16}$ is $12.2 \mathrm{~ns}$ in hexane solution. The free sulfonic acid derivative has a fluorescence lifetime of $13 \mathrm{~ns}$ in alkaline aqueous solutions and shows a monoexponential decay. ${ }^{25}$ This and many others are examples of fluorescent probes placed in a homogeneous environment for which a monoexponential decay is expected because of the absence of complex photophysical processes like excimer or exciplex formation, long range energy transfer, or diffusioncontrolled quenching. In heterogeneous systems, a multiplicity of interactions with different local environments is quite likely to give raise to a multiplicity of decay times and therefore to a continuous distribution of lifetimes. ${ }^{26}$ Nevertheless, as will be discussed below, in our samples it is not justified to explain the photophysical results in terms of a distribution of environmental sites at which the dansyl moiety is attached.

In Table III, it can be observed that fluorescence lifetimes have values around 4.5 and $14 \mathrm{~ns}$. This fast and slow components change its contribution between 16 and 593 for the former and between 41 and 843 for the later. In accordance with the twostate model, ${ }^{27}$ the longest component Tz may correspond to the emission from the relaxed state and therefore its contribution must be the highest when decays are collected in the red-edge of the emission spectra (around $495 \mathrm{~nm}$ for this samples ). For the samples silanized by aqueous APES solutions, either polymerized at low or at high temperature, this is just what it is observed. Also in accordance with this model, it is observed that the shortest component $T_{1}$ has its maximum contribution when decays are collected in the blue-edge of the emission spectra, although the longest contribution is always higher with the exception of sample VAP1O.

If it is assumed that the two-state model operates in this system and that Tz corresponds to the emission from the relaxed state, then the solvent relaxation lifetime $T R$ may be calculated according to ${ }^{27}$ $T I ?^{1}=T I^{\prime}-T 2^{1}$. The results from this calculation appear in the next to last column of Table Ill. For the samples silanized in aqueous solutions, $T R$ remains almost constant around $7.7 \mathrm{~ns}$, within the experimental error, independently of the silanization time or polymerization temperature. These values are of the same order of magnitude, although slightly greater, than the dielectric relaxation time of pure APES, ${ }^{28}$ which is $1.8 \mathrm{~ns}$, meaning that in the relaxation process the APES moiety probably is involved as a whole and that the mechanism of molecular relaxation must be the same for all the samples. Therefore, at the very local level from which the dansyl probe provides information, the microenvironment is not altered by the two preparative variables used in this work: silanization time and polymerization temperature. In other words, this two preparative variables modify the structure of the polyorganosiloxane layer ( in accordance with our FTIR results) but in a length scale larger than the 

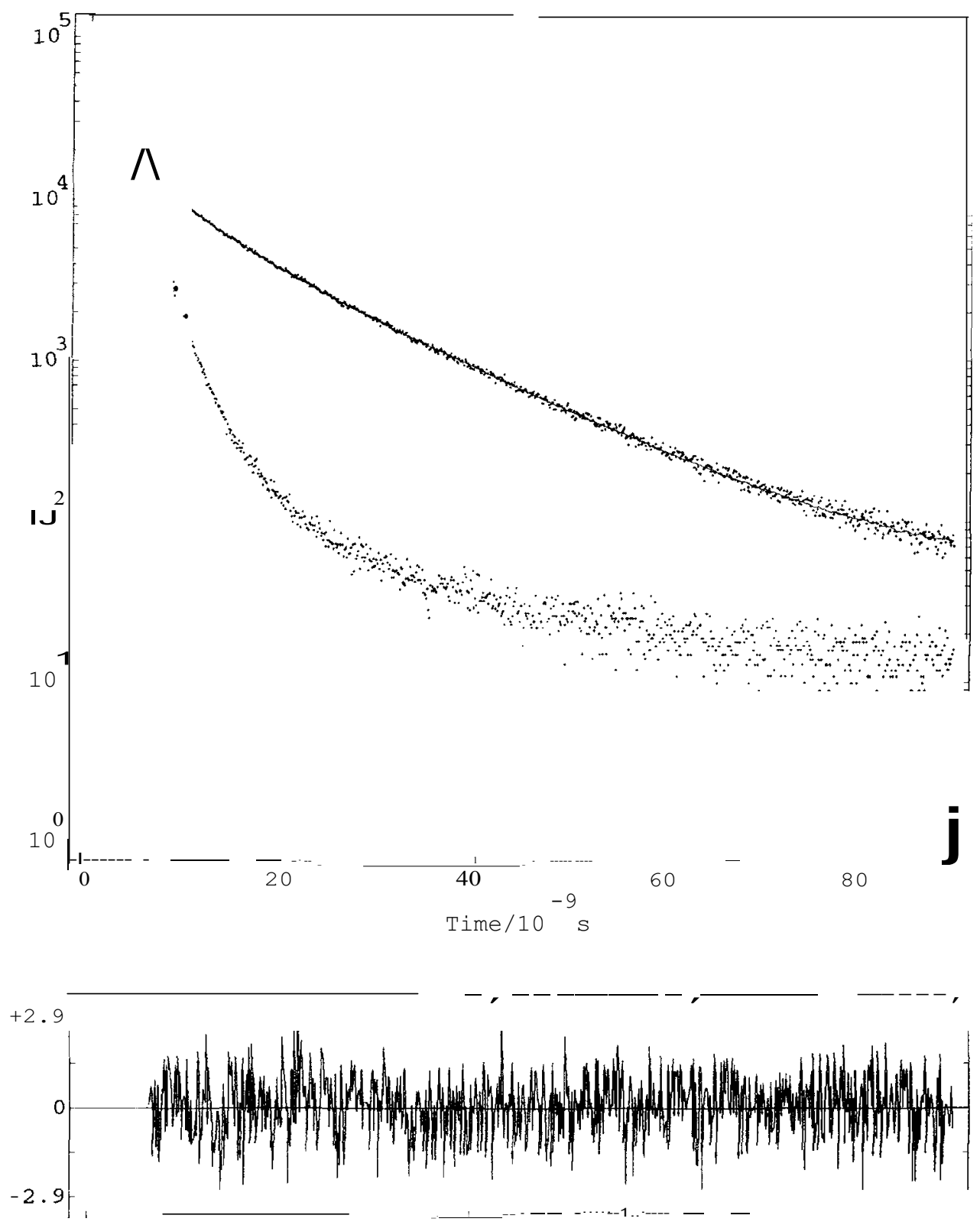

Figure 7 Fluorescence decay of a representative sample. The line represents the best three exponential fitting function. Points scattering around the line represent the sample response; the lamp profile appears superimposed. Weighted residuals are drawn below.

characteristic scale length for photophysical relaxation.

The samples silanized by vapor adsorption of APES show some differences when compared with aqueous treatments. It seems that silanization time effectively modifies the dansyl microenvironment, although a two-state model for this sample seems to operate also; at short treatment times, it is found to be a very great contribution of $7_{2}(60 \%)$, and, as a consequence, this sample displays the shortest average lifetime ( $6 \mathrm{~ns}$ ) and the shortest relaxation time
(4.3 ns) of all samples studied in this work. This result indicates a more pronounced flexibility of the polymer layer that may be due to a small coverage degree. On the other hand, at long treatment times the contribution of $7_{1}$ is very high (almost the same that sample AQ30-120) and the relaxation time seems to be also very high, indicating a more rigid environment of the probe. This is in accordance with our previous FTIR result, since for this sample it was observed a high crosslinking degree of the coating layer. More work is being planned to check if 
Table III $T$, Integrated Amplitudes $w$, Relaxation Time $T R$, Average Lifetime (T), and Chi Square Values for Biexponential Fittings of Dansylated Samples

\begin{tabular}{|c|c|c|c|c|c|c|c|c|}
\hline Sample & $\begin{array}{l}\text {, IEM } \\
(\mathrm{nm})\end{array}$ & $x^{2}$ & $\begin{array}{c}\mathrm{Ti} \\
(\mathrm{ns})\end{array}$ & $\begin{array}{c}\mathrm{T} 2 \\
(\mathrm{~ns})\end{array}$ & $\begin{array}{c}\text { W1 } \\
(\%)\end{array}$ & $\begin{array}{c}\text { W2 } \\
(\%)\end{array}$ & $\begin{array}{c}T R \\
(\mathrm{~ns})\end{array}$ & $\begin{array}{l}\langle\mathrm{T}\rangle \\
(\mathrm{ns})\end{array}$ \\
\hline \multirow[t]{3}{*}{ AQ30-120 } & 420 & 1.042 & $6.5 \pm 0.5$ & $14.1 \pm 0.5$ & $32 \pm$ & $68 \pm 9$ & & \\
\hline & 455 & 1.143 & $4.9 \pm 0.2$ & $14.0 \pm 0.1$ & $16 \pm$ & $84 \pm 2$ & $7.5 \pm 0.5$ & $12.5 \pm 0.2$ \\
\hline & 496 & 1.091 & $5.2 \pm 0.3$ & $15.4 \pm 0.2$ & $20 \pm 3$ & $80 \pm 3$ & & \\
\hline \multirow[t]{3}{*}{ AQ15-120 } & 417 & 1.019 & $4.8 \pm 0.3$ & $13.7 \pm 0.4$ & $38 \pm 8$ & $62 \pm 8$ & & \\
\hline & 452 & 1.082 & $5.3 \pm 0.3$ & $14.8 \pm 0.3$ & $26 \pm 5$ & $74 \pm 5$ & $8.3 \pm 0.8$ & $12.3 \pm 0.4$ \\
\hline & 495 & 1.032 & $5.5 \pm 0.3$ & $16.0 \pm 0.3$ & $22 \pm 4$ & $78 \pm 4$ & & \\
\hline AQ5-120 & 451 & 1.092 & $5.3 \pm 0.2$ & $15.9 \pm 0.2$ & $33 \pm 4$ & $67 \pm 4$ & $8.0 \pm 0.5$ & $12.4 \pm 0.3$ \\
\hline \multirow[t]{3}{*}{ AQ30-60 } & 420 & 0.970 & $3.4 \pm 0.2$ & $13.1 \pm 0.2$ & $33 \pm 7$ & $67 \pm 7$ & & \\
\hline & $45 ; 3$ & 0.885 & $4.6 \pm 0.3$ & $14.6 \pm 0.2$ & $24 \pm 4$ & $76 \pm 4$ & $6.7 \pm 0.7$ & $12.2 \pm 0.4$ \\
\hline & 495 & 1.027 & $4.3 \pm 0.3$ & $14.9 \pm 0.2$ & $18 \pm 3$ & $82 \pm 3$ & & \\
\hline \multirow[t]{3}{*}{ AQ15-60 } & 417 & 0.988 & $3.3 \pm 0.1$ & $12.7 \pm 0.3$ & $49 \pm 8$ & $51 \pm 8$ & & \\
\hline & 452 & 1.020 & $4.7 \pm 0.2$ & $14.9 \pm 0.3$ & $32 \pm 5$ & $68 \pm 5$ & $6.9 \pm 0.5$ & $11.6 \pm 0.3$ \\
\hline & 495 & 1.141 & $3.8 \pm 0.1$ & $14.9 \pm 0.1$ & $22 \pm 2$ & $78 \pm 2$ & & \\
\hline AQ5-60 & 448 & 0.986 & $5.5 \pm 0.6$ & $15.4 \pm 0.7$ & $35 \pm 11$ & $65 \pm 11$ & $8.6 \pm 1.7$ & $12 \pm 1$ \\
\hline VAPIO & 459 & 0.976 & $3.0 \pm 0.1$ & $10.1 \pm 0.2$ & $59 \pm 7$ & $41 \pm 7$ & $4.3 \pm 0.2$ & $5.9 \pm 0.3$ \\
\hline VAP60 & 458 & 0.977 & $5.7 \pm 0.2$ & $14.0 \pm 0.1$ & $18 \pm 3$ & $82 \pm 3$ & $9.6 \pm 0.6$ & $12.5 \pm 0.2$ \\
\hline
\end{tabular}

the vapor adsorption method may be a good form for obtaining more uniform coating layers with selectable thickness as a function of treatment time, even with trifunctional silanes.

\section{CONCLUSIONS}

Silanization of glass fibers by reflux of a toluene APES solution is not an efficient process. Silanization with APES aqueous solutions at their natural $\mathrm{pH}$ yields a slightly crosslinked polysiloxane fiber coating, leaving the amine residues mostly in its protonated form. Silanization time (for $t$ higher than $5 \mathrm{~min}$ ) or polymerization temperature (between 60 and $120^{\circ} \mathrm{C}$ ) do not change the coating microstructure at a length scale of the order of the dansyl moiety diameter. Silanization by APES vapor adsorption gives a place to polymer coats with a crosslinking degree that may be a function of treatment time. From a photophysical point, a two-state model for the solid solvent relaxation seems to apply for this systems.

Financial support for this work has been provided by Comision Interministerial de Ciencia y Tecnologia ( ClCYT ), under grant MAT93-0823, and by Comunidad Aut6noma de Madrid (CAM), under grant 247/92. We thank Dr. I. Pierola for her comments and suggestions.

\section{REFERENCES}

1. K. L. Mittal, Silanes and Other Coupling Agents, JSP, Ed. Utrech, 1992.

2. W. Noll, Chemistry and Technology of Silicones, Academic Press, London, 1968.

3. R. K. Iler, The Chemistry of Silica, John Wiley, New York, 1979.

4. A. T. Di Benedetto and D. A. Scola, J. Colloid Interface Sci., 64, 565 (1978) .

5. W. D. Bascom, M acromolecules, 5, 792 ( 1972 ).

6. B. S. Jacobson, J. Cronin, and D. Branton, Biochim. Biophys. Acta, 506, 81 ( 1978).

7. A. J. Kinloch, Structural Ad hesives: Developments in Resins and Primers, Elsevier Appl. Sci. Pub., London, 1986.

8. N. Ikuta, Y. Suzuki, Z. Maekawa, and H. Hamada, Polymer, 34, 2445 ( 1993).

9. E. P. Plueddemann, Silane Coupling Agents, Plenum Press, New York, 1982.

10. P. G. Pape and E. P. Plueddemann in Silanes and Other Coupling Agents, K. L. Mittal, Ed., VSP, Utrecht, 1992.

11. A. Chateauminois, L. Vincent, B. Chabert, and J. P. Soulier, Polymer, 35, 4766 (1994).

12. H. Morawetz, in New Trends in The Photochemistry of Polymers, N. S. Allen and J. F. Rabek, Eds., Elsevier Appl. Sci. Pub., London, 1985.

13. P. Van Der Voort, I.Gillis-D'Hamers, K. C. Vrancken, and E. F. Vansant, J. Chem. Soc., Faraday Trans., 87' 3899 (1991).

14. G. Socrates, Inf rared Characteristic Group Frequencies, John Wiley \& Sons, Chichester, England, 1994,p. 189. 
15. V. C. Farmer, The Infrared Spectra of Minerals, Mineralogical Society, London, 1972.

16. R. P. Haugland, Handbook of Fluorescent Probes and Research Chemicals, Larison Ed., Eugene, 1992.

17. K. J. Shea, D. Y. Sasaki, and G. J. Stoddard, Macromolecules, 22, 1722 ( 1989).

18. K. J. Shea and G. J. Stoddard, Polym. Prepr., 24, 350 (1988) .

19. K. J. Shea, Y. Okahata, and T. K. Dougherty, Macromolecules, 17, 296 (1984).

20. C. H. Lochmiiller, D. B. Marshall, and D. R. Wilder, Anal. Chim. Acta, 130, 31 ( 1981).

21. E. Carlier, A. Revillon, A. Guyot, and J. Chauvet, Eur. Polym. J., 29, 819 (1993).

22. E. Carlier, A. Revillon, and J. Chauvet, Eur. Polym. J., 29, 825 (1993).

23. J. Brandrup and E. H. lmmergut, Polymer Handbook, Wiley, New York, 1989.
24. J. R. Lakowicz, Principles of Fluorescence Spectroscopy, Plenum Press, New York, 1986, p. 218.

25. K. Kalyanasundaram, in Photochemistry in Organized and Constrained Media, Ramamurthy Ed., Chap. 2, VCH, New York, 1991, pp. 39-78.

26. Th. Binkert, J. Oberreich, M. Meewes, R. Nyffenegger, and J. Ricka, Macromolecules, 24, 5806 ( 1991) .

27. A. P. Demchenko, Fluorescence and Dynamics in Proteins, in Topics in Fluorescence Spectroscopy, Vol. 3, De. J. R. Lakowicz, Ed., Plenum Press, New York, 1992.

28. $r v$ of pure APES may be calculated, assuming spherical geometry, by means of Debye's equation, $r v$ $=4 \ln 7 a^{3} / k T$, as calculated in K-F. Lin and F. W. Wang, Polymer, 35, 687 (1994). 